\title{
Los relatos iconográficos en la revitalización de la lengua kichwa en la unidad educativa intercultural bilingüe intillacta
}

\author{
Heidy Sara Lara Catagña (Estudiante) ${ }^{1}$ \\ heidykiss@ hotmail.com \\ Maestrante - Maestría en Educación con mención en Innovación \\ y Liderazgo Educativo - Cohorte 6 - \\ Universidad Tecnológica Indoamérica. \\ Walter Fernández Ulloa Mg. (Tutor) ${ }^{2}$ \\ walterfernandez@uti.edu.ec \\ Profesor Tutor - Maestría en Educación con mención en Innovación \\ y Liderazgo Educativo, \\ Universidad Tecnológica Indoamérica
}

\section{RESUMEN}

Este proyecto de investigación sobre "Los relatos iconográficos en la revitalización de la lengua kichwa", indaga sobre la necesidad de generar recursos y estrategias pedagógicas para las nuevas generaciones, en especial la indígena de la provincia de Napo, en su propia lengua y costumbres para promover el uso educativo de este idioma que se encuentra en peligro de extinción. Se propuso como objetivo recuperar los relatos iconográficos propios para la revitalización de la lengua kichwa, se utilizó la metodología descriptiva y también técnicas e instrumentos como encuestas y fichas de observación empleadas en la recopilación de información proporcionada por los preadolescentes del séptimo año de la Unidad Educativa Intercultural Bilingüe Intillacta. Se identificó, en los resultados de la representación gráfica, las leyendas y tradiciones que conservan los estudiantes; así mismo, se evidencio que los docentes a través de sus actividades permiten mantener vivo el uso de la lengua de la cultura kichwa amazónica entre los jóvenes y las nuevas generaciones.

Con los relatos identificados más tarde se desarrolló una herramienta pedagógica de revitalización del uso del idioma, permitiendo valorar la identidad cultural y una ampliación de espacios lingüísticos del hablante, además se identificó la figura histórica de "Jumandi" como parte de las tradiciones orales e icónicas de la amazonia en el contexto del territorio kichwa del oriente ecuatoriano, parroquia y cantón Tena de la provincia de Napo. 
Finalmente, se concluye que la utilización de instrumentos iconográficos como: cómic, caricaturas, cine, etc. revitalizan las tradiciones y costumbres de un pueblo, además de ser importante para motivar el aprendizaje entre estudiantes y docentes; posibilita una autentica revitalización de la lengua original kichwa, utilizada por los antepasados, motivando su uso en el sistema educativo intercultural bilingüe de nuestro país.

Palabras claves: comic; cultura kichwa; educomunicación; iconografía; relatos iconográficos. 


\title{
The iconographic stories in the revitalization of the Kichwa language in the intillacta bilingual intercultural educational unit
}

\begin{abstract}
This research project on "Iconographic stories in Kichwa language revitalization", investigates the need to generate resources and pedagogical strategies for the new generations, especially the indigenous one in Napo province, in their own language and customs to promote the educational use of this endangered language. The objective was to recover the iconographic stories in Kichwa language revitalization. The descriptive methodology was used, as well as techniques and instruments such as surveys and observation sheets used in the collection of information provided by the preadolescents of the seventh year of "Intillacta" intercultural bilingual school. It was identified, in the results of the graphic representation, the legends and traditions that the students preserve. Likewise, it was evidenced that teachers, through their activities, allow the use of the language of the Amazonian Kichwa culture to be kept alive among young people and new generations.

With the stories identified later, a pedagogical tool was developed to revitalize the use of the language, allowing to assess the cultural identity and an expansion of the linguistic spaces of the speaker, in addition the historical figure of "Jumandi" was identified as part of the oral and iconic traditions of the Amazon in the context of the Kichwa territory of eastern Ecuador, the parish and Tena canton of the Napo province.

Finally, it is concluded that the use of iconographic instruments such as: comics, cartoons, cinema, etc. they revitalize the traditions and customs of a people, as well as being important.
\end{abstract}

Keywords: comic, kichwa culture, educommunication, iconography.

Artículo recibido: 02 enero 2022 Aceptado para publicación: 28 enero 2022 Correspondencia: heidykiss@hotmail.com Conflictos de Interés: Ninguna que declarar 


\section{INTRODUCCIÓN}

Conforme a lo dispuesto en el Plan Nacional de Buen vivir, dentro de los objetivos nacionales, el "eje 1: Derechos para todos durante toda la vida", objetivo 2: "Afirmar la interculturalidad y plurinacionalidad, revalorizando las identidades diversas"; compete a la investigación que la cultura kichwa necesita ser revalorizada utilizando las nuevas estrategias para preservar su identidad. (Desarrollo, 2017).

El Plan de Desarrollo Amazónico, enmarca a los derechos individuales con mirada intercultural, para reivindicar los derechos de las diferentes nacionalidades, respetando las características individuales socio-culturales propias de los habitantes de la región. Busca reducir la extinción de las lenguas ancestrales incluido el kichwa que según Cabascango esta se extinguiría en 30 años aproximadamente (FAO, 2016); se espera que al difundir relatos de la cultura kichwa utilizando la tecnología, se pueda evitar la extinción del idioma.

Los pueblos de la Amazonía ecuatoriana tienen vulnerabilidad en el entorno en el que viven; los kichwa tienen una población hablante de 590000 personas (FAO, 2016), este idioma podría desaparecer frente al uso del castellano y con la llegada de personas foráneas, van perdiendo su identidad idiomática. El revalorizar, utilizar nuevas estrategias e innovar la forma de contar relatos propios de su cultura, captará la atención de las nuevas generaciones que ya utilizan tecnologías y dominan el alfabeto para comunicarse.

\section{Interrogantes de la investigación}

- ¿Qué relatos iconográficos propios revitalizan la lengua Kichwa, durante el año 2020-2021 en el nivel básico medio, séptimo año de la Unidad Educativa Intercultural Bilingüe Intillacta, de la parroquia Tena, Cantón Tena de la provincia de Napo?

- ¿Cuáles son los relatos propios que valorizan la cultura y la lengua Kichwa?

- ¿Qué importancia tienen las narraciones escritas en lengua Kichwa para revitalizar la cultura?

- ¿Qué tipo de relatos iconográficos propios podrían revitalizar la cultura Kichwa?

\section{Delimitación espacial}

Unidad Educativa Intercultural Bilingüe "Intillacta", ubicada en la provincia de Napo de la región amazónica del Ecuador ha participado en programas socio 
culturales con actos donde usa el idioma kichwa, tanto a nivel cantonal, provincial y nacional. Busca no perder las costumbres ni el idioma de su cultura.

\section{Delimitación temporal}

El trabajo de investigación se realizó durante el año lectivo 2020-2021.

\section{Unidades de estudio}

Estudiantes y docentes

\section{Objetivos}

\section{Objetivo General}

- Recuperar los relatos iconográficos propios que revitalizan la lengua Kichwa, en la Unidad Educativa Intercultural Bilingüe "Intillacta”, subnivel básico medio del séptimo año durante el tercer parcial del segundo quimestre del año lectivo 2020-2021.

\section{Objetivos específicos}

- Identificar relatos propios para valorizar la cultura y la lengua Kichwa.

- Describir la importancia de las narraciones escritas en su lengua propia para revitalizar la cultura Kichwa.

- Proponer un diseño un relato iconográfico propio de la cultura Kichwa.

\section{DESARROLLO}

\section{Marco teórico}

\section{La iconografía secular}

El cómic dentro del género de las artes ha sido el género menos estudiado; no se le ha dado importancia, incluso se lo ha llegado a considerar indigno; Rubén Varillas (como se citó en Fernández Nerea, 2017) piensa que estamos ante una disciplina joven y minoritaria.

Traen consigo historias, que son contadas desde diferentes perspectivas, las mangas que se generan permiten desarrollar argumentos con amplitud de ideas. Generalmente, al leer y ver un cómic se desarrolla una trama donde es común ver un héroe que según Fernández (2017) los define de la siguiente manera dentro del cómic:

Los héroes y superhéroes no son simples personajes de una narración cuya finalidad es predominante recreativa y estética, sino que el rostro del héroe es el reflejo del nuestro y el sentimiento de verse representado en el personaje de ficción ocurre en 
muchos lectores, en parte gracia a que se trata de un producto hipnótico de la cultura de masas. Amamos a los superhéroes porque no nos fallan, porque podemos analizarlos, negar su existencia, matarlos, prohibirlos, reírnos de ellos.

\section{Lenguas originarias}

Según el Ministerio de Educación del Perú (como se citó en Chávez, Chenet, Quispe, 2019), las lenguas originarias pueden ser clasificadas en: lenguas vitales, lenguas en peligro, lenguas seriamente en peligro. Juntamente con la nomenclatura de la UNESCO, y varios especialistas lingüistas se realizan ciertas modificaciones:

Tabla 1. Clasificación de lenguas originarias

\begin{tabular}{ll}
\hline \multicolumn{1}{c}{ AGRUPACIÓN } & \multicolumn{1}{c}{ Descripción } \\
\hline Lenguas vitales & $\begin{array}{l}\text { Son las que se hablan de generación en generación en una } \\
\text { comunidad, donde su transmisión es común. Siendo utilizadas } \\
\text { en casi todos los ámbitos de comunicación. }\end{array}$ \\
\hline Se hablan en las personas adultas de una determinada \\
Lenguas en peligro \\
$\begin{array}{l}\text { comunidad; la lengua se restringe a ciertos espacios de la } \\
\text { comunicación, se transmite de forma parcial en ciertas } \\
\text { comunidades. }\end{array}$ \\
\hline $\begin{array}{l}\text { Lenguas } \\
\text { seriamente en } \\
\text { peligro }\end{array}$ & $\begin{array}{l}\text { Son las que hablan, solo entre las personas adultas mayores, o } \\
\text { sea la tercera edad y de modo parcial, con escasa frecuencia }\end{array}$ \\
\hline
\end{tabular}

Elaborado por: Heidy Lara C.

Fuente: (Chávez, Chenet, Quispe, 2019)

\section{Lengua Kichwa}

Hablan Kichwa amazónico las siguientes provincias, como se muestra a continuación:

Figura 1 Tomado del gráfico $N^{o} 9$ Mapa de lenguas indígenas, Amazonía del Ecuador

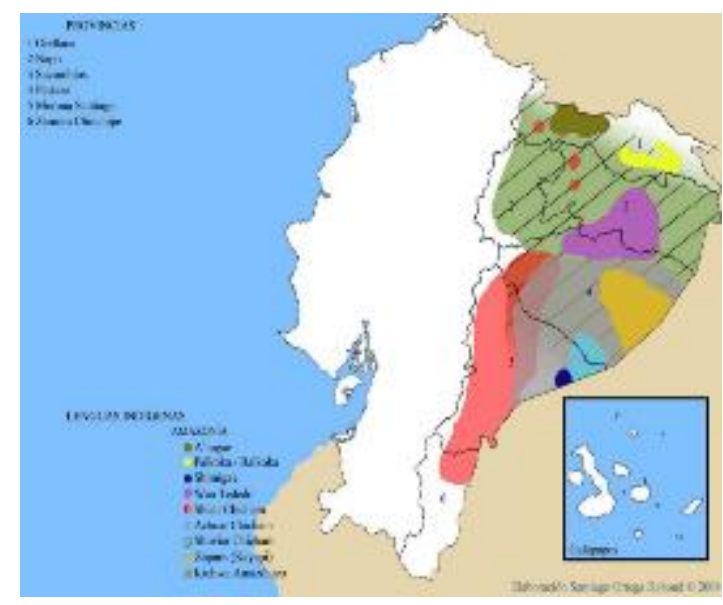

Fuente: PUCE, 2008. 
En las provincias amazónicas: Sucumbíos, Napo, Orellana y parte de Pastaza, reflejadas con el color verde con rayas verticales en el gráfico anterior. De acuerdo con la CONAIE, (2014) la lengua materna es el Kichwa y la segunda lengua es el español, esto como recuerdo de la colonización de los españoles.

\section{Revitalización de la lengua}

La revitalización lingüística, según Grenoble \& Whalry (como se citó en López V. \& Koshinen A., 2009) se resume de la siguiente manera: "las lenguas son tesoros culturales y patrimonio histórico; diversidad linguiística y diversidad cultural, estimula el pensamiento innovador y presenta maneras alternativas del ver el mundo; las lenguas son parte de derechos humanos; son portadoras de conocimientos sobre la diversidad biológica" ( $\mathrm{p} 10)$.

Gracias a las lenguas podemos conocer otros pensamientos del mundo y permiten la diversidad cultural; su revitalización está relacionada con nuevas formas de crear e innovar alternativas de transmisión y permanencia del idioma por más años.

Revitalizar significa revalorar y reafirmar nuestra identidad; según (Facultad Latinoamericana de Ciencias Sociales Ecuador, 2014). Se puede hacer esto potencializando las manifestaciones culturales; esto se lleva a la práctica al difundir la historia y pasando de la oralidad a la escritura.

\section{Didáctica Escrita para revitalizar el idioma}

Es una apuesta didáctica la producción de textos para aprendizaje bilingües, que según Charaudeau y Granato (como se citó en García-Azkoaga, 2019) permiten:

Conocer las reglas gramaticales, la capacidad para producir frases bien estructuradas no garantiza un funcionamiento comunicativo de la lengua. La concreción empírica de la comunicación es el texto y debe ser la unidad objeto de análisis y de aprendizaje. Si bien este punto de vista social del lenguaje es compartido por muchos autores, su práctica está llena de matices y ha sido abordada de diferentes maneras (p. 54).

Utilizar los géneros textuales sirven como herramienta didáctica que según Dolz, Gagnon, Mosquera y Sánchez (como se citó en García-Azkoaga, 2019), facilitan al estudiante el tener acceso a varios significados que, si son interiorizados, mejorarán sus capacidades lingüísticas. Más allá la práctica educativa requiere de dispositivos que permitan analizar y utilizar los textos como objeto de aprendizaje. 
Existe una experiencia de revitalización de la lengua utilizando la escritura en el País Vasco; probablemente se puede asegurar que la revitalización lingüística de esta lengua se debe a la medida en que la escuela dedica más tiempo a los aprendizajes en la lengua más desfavorecida (García A., 2019).

Por lo investigado de acuerdo con las respuestas arrojadas de los instrumentos aplicados, podemos clasificar a los relatos de la cultura kichwa del oriente ecuatoriano de la siguiente manera:

- Relatos de héroes (Jumandi, Guami, Beto y otros personajes que observan como líderes)

- Relatos de historias de mujeres (siembras, Cumandá, vivencias)

- Relatos sobre animales (Puma, Tortuga, boa, y otros animales con los que ellos están relacionados habitualmente en la selva)

- Relatos sobre la naturaleza (árboles, plantas, guayusa, ayahuasca, flores)

- Relatos sobre los astros (Sol, luna, estrellas).

De tal forma que existe una variedad muy amplia de relatos por transcribir y explorar. La transmisión es oral en su mayoría, los conocimientos que aún tienen en sus pensamientos la generación de adolescentes del año lectivo 2020-2021, de la Unidad Educativa Intercultural Bilingüe "Intillacta", a la realidad son los últimos, porque entienden el idioma y ya no lo practican; es importante transcribir para dejar una huella en la literatura indígena, aportar a la revitalización del idioma y conservar la cultura para más generaciones.

\section{Paradigma y tipo de investigación}

El presente trabajo de investigación utilizó el paradigma mixto cuanti-cualitativo, porque se cuantificará mediante una población datos e información.

La metodología que se aplicó en la es el método descriptivo, el cual permitirá describir y definir los relatos iconográficos como estos pueden revitalizar el idioma.

Se utilizó la modalidad aplicada por cuanto los objetivos del trabajo llevan a presentar una propuesta de desarrollo, como resultado de la investigación. Para dar mayor realce y refuerzo al marco teórico, se utilizó información y datos de manuales, libros, revistas, artículos científicos, fuentes de internet confiables que se convirtieron en información primaria y de gran importancia. Los tipos de investigación fueron: 


\section{Exploratorio}

Se exploró conocimientos de revitalización del idioma, cuáles son las estrategias más actuales para aplicar y cuales han dado excelentes resultados.

\section{Descriptivo}

El nivel de profundidad de la investigación que se utilizó fue el nivel descriptivo, porque se trabajó con la variable que describirá (relatos iconográficos) fenómenos sociales en una circunstancia temporal con el fin de estimar parámetros.

\section{Población y muestra}

Se trabajó con la población total del séptimo año y sus docentes, 21 estudiantes; y 2 docentes. Se escogió el nivel básico medio y el séptimo año, por la pandemia y los datos de acceso a comunicación virtual también al recibimiento de fichas pedagógicas una vez por semana constantemente; donde el tutor interactúa con estudiantes tanto en comunicación directa como por medio de la plataforma Zoom.

\section{Procedimiento de recolección de la información}

\section{Métodos}

La metodología que se va a aplicar en la presente investigación es el método descriptivo, el cual nos permitirá describir y definir los relatos iconográficos como estos pueden revitalizar el idioma.

\section{Técnicas e instrumentos}

Encuesta: se aplicará la técnica de la encuesta con un instrumento de cuestionario direccionado a estudiantes del séptimo año del nivel básico medio paralelo "único"; para describir y definir que relatos iconográficos propios son los más representativos de los estudiantes de la Unidad Educativa Intercultural Bilingue Intillacta.

Observación: además se aplicará la técnica de la observación con el instrumento de visita aúlica de docentes de séptimo año, paralelo "único"; para definir cuál es el uso del idioma dentro de la clase y su contribución en la revitalización del mismo.

Como última instancia se realizará la recolección de datos aplicados a los estudiantes del séptimo año, paralelo "único" de la Unidad Educativa Intercultural Bilingue Intillacta.

\section{Validación de la aplicación práctica de la propuesta}

Validez: El presente análisis se desarrolla a partir de entrevistas realizadas al grupo focal que corresponde a estudiantes y docente del séptimo año de educación básica 
de la unidad educativa intercultural bilingüe Intillacta, respecto a la aplicación del producto, cómic "Jumandi hijo del Sumaco (Sumakupak churi)"

\section{RESULTADOS Y DISCUSIÓN}

\section{Investigación realizada a estudiantes}

\section{Nombre del relato contado por sus padres o abuelos}

Figura 2 Pregunta 7- Nombres de relatos contados.

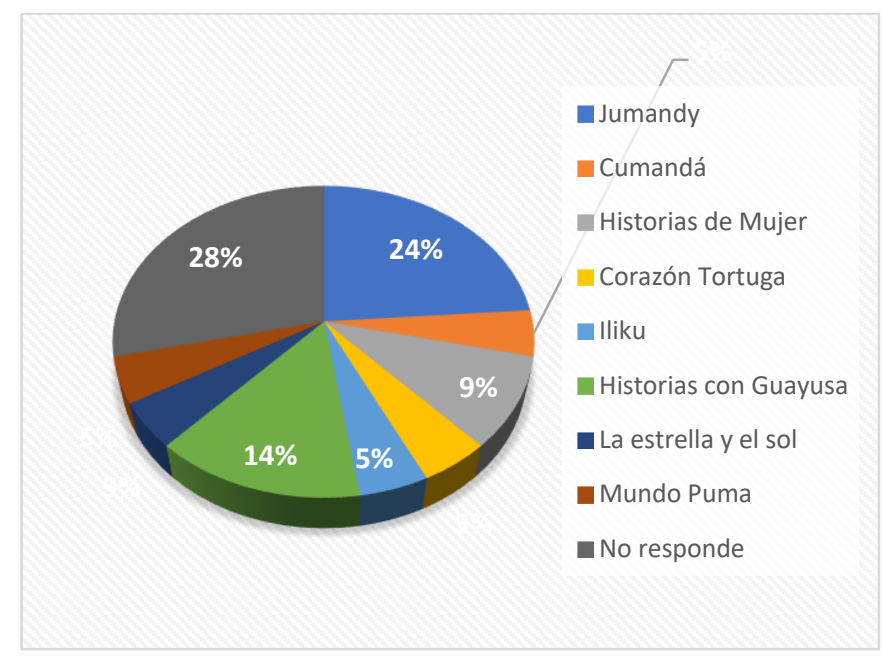

Autor: Lara H., 2021.

Fuente: Encuesta aplicada a estudiantes.

\section{Análisis e interpretación}

De la encuesta aplicada a 21 estudiantes del subnivel medio de séptimo año de la Unidad Educativa Intercultural Bilingüe "Intillacta", se determina que: 6 estudiantes no responden a esta pregunta y representan el 29\%; 5 escriben que el nombre del relato que les contaban sus padres y abuelos era Jumandi representando el 24\%; 3 estudiantes responden que el nombre del relato es Historias con Guayusa representando el 14\%; 2 estudiantes responden que los nombres de relatos eran historias de mujeres representando el 9\%; 1 estudiante responde que el nombre del relato que les contaban sus padres y abuelos era Cumandá representando el 5\%; 1 estudiante menciona que el nombre del relato es Corazón tortuga representando el $5 \% ; 1$ estudiante escribe que el nombre de relato que le contaban es Iliku con el 5\%; 1 estudiante escribe el nombre del relato es la Estrella y el Sol representando el 5\%; 1 estudiante menciona que el nombre del relato es Mundo Puma y representa el 5\%.

De acuerdo con los resultados obtenidos la mayoría de los estudiantes no responden a escribir el nombre de un relato, desconocen un título, o no pueden definir el nombre 
del relato. El porcentaje que le sigue es el nombre del relato de Jumandi. Lo que se traduce en un posicionamiento en la mente de esta generación de dicho relato, por lo que a los estudiantes de esta generación les ha llegado el relato hasta nuestros días (Landa A., 2011).

\section{2. ¿Qué materiales utilizan para la enseñanza de la lengua y alfabetización?}

Figura 3 Pregunta 6-Materiales de enseñanza de la lengua.

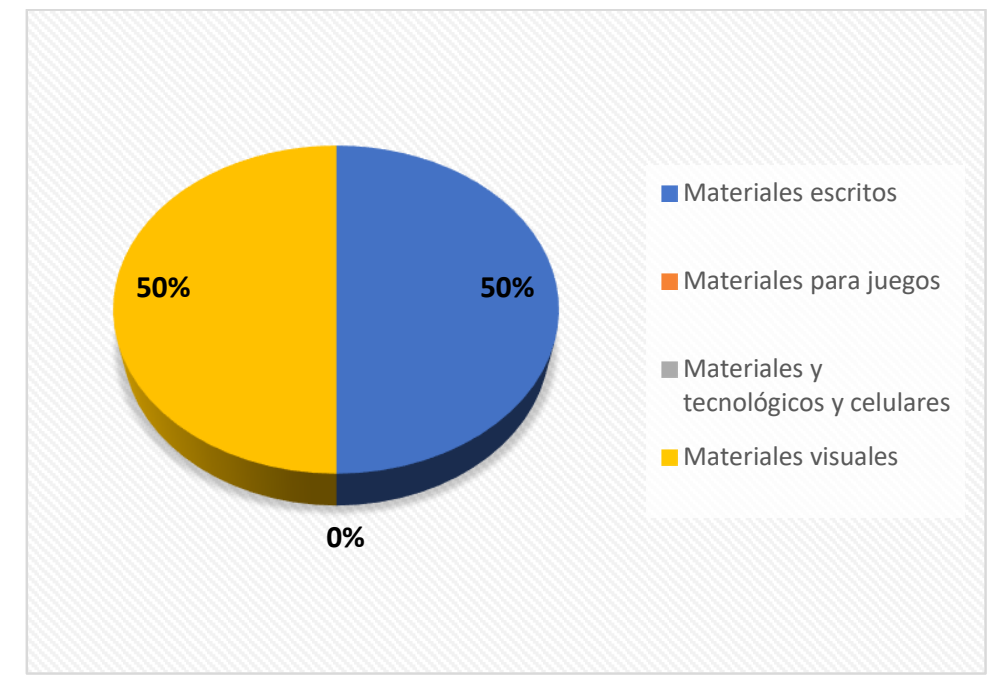

Autor: Lara H., 2021.

Fuente: Ficha de observación aplicada a docentes.

\section{Análisis e interpretación}

Para desarrollar mejor la clase, practicar y promover el uso del idioma es indispensable contar con más materiales escritos con el $50 \%$ y promover el uso de materiales visuales con el $50 \%$ restante de la ficha observada, durante la hora clase.

En relación con los datos obtenidos, podemos mencionar que durante la hora clase virtual, no existe material escrito a proyectar, tampoco hay material visual en el idioma kichwa que fortalezca el uso y posicionamiento del idioma. Los docentes imparten la clase más de forma oral. Es importante que el Estado desarrolle la pedagogía en función de las características lingüísticas, culturales, históricas de cada nacionalidad indígena, permitiendo una mayor práctica del idioma en los espacios de la unidad educativa y en el tiempo de la hora virtual para tener una educación intercultural bilingüe, adecuada para los pueblos y las nacionalidades. (Ministerio de Educación, 2021) 


\section{Propuesta de solución}

El producto diseñado, es un relato iconográfico propio de la cultura kichwa de la amazonía ecuatoriana, transmitido a través de un cómic de 8 páginas. Para fortalecer la identidad cultural de las nuevas generaciones, se ha elaborado con imágenes animadas, colores atractivos, y la historia redactada en su idioma original. Llama la atención en especial de los preadolescentes que dominan las destrezas de la observación, lectura y escritura.

Figura 4 Gráfico 43-Portada cómic Jumandi.

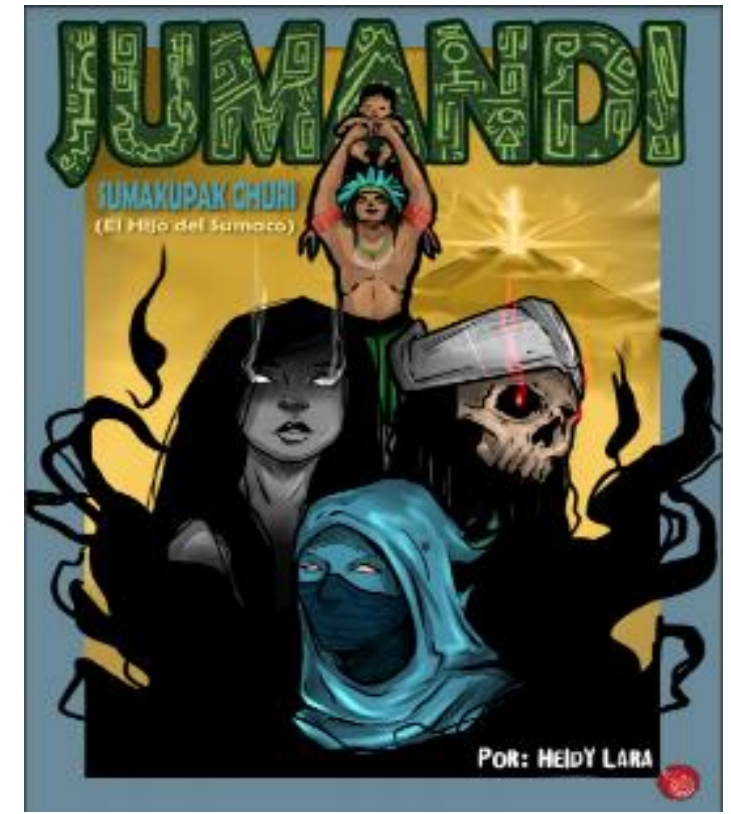

Elaborado por: Lara H., 2021.

\section{Nombre de la propuesta}

Cómic: "Jumandi el hijo del Sumaco"

\section{Definición del tipo de producto}

Es un cómic de 8 páginas con 15 planas, que se puede encontrar en dos presentaciones, tanto de forma virtual como impresa. Contiene el relato iconográfico más conocido sobre hazañas de guerra del héroe indígena Jumandi. En el primer capítulo que se desarrolla, trata sobre el nacimiento del héroe. Es un trabajo visual lleno de paisajes, imágenes y personajes que captan la atención de los preadolescentes y adolescentes. En la parte de los diálogos y secuencia escrita de la historia, se ha preferido redactar en el idioma kichwa, para incentivar la práctica de la lengua en las nuevas generaciones, tanto la lectura, y la valoración de la identidad. 


\section{Explicación de cómo la propuesta contribuye a solucionar las insuficiencias} identificadas en el diagnóstico.

El cómic "Jumandi el hijo del Sumaco", sirve como un material didáctico visualescrito, para utilizarse en unidades educativas bilingües, en preadolescentes interesados en los dibujos animados. Sus docentes lo pueden usar como material visual-escrito para enseñanzas en áreas como Lengua y Literatura, Ciencias Sociales, Educación Cultural y Artística. Con ello se fomentarían la lectura, la escritura y la práctica oral del idioma dentro de las horas clase, utilizando una herramienta innovadora pedagógica.

\section{Premisas para su implementación}

El modelo educativo para aplicar es: el sociocontructivismo, pues el ser humano actúa sobre su realidad y ésta le permite transformarse así mismo a través de herramientas mediadoras como el lenguaje (Palomino J., 2017). En este modelo lo más importante es el lenguaje pues permite la interacción social; el estudiante necesita dominar el lenguaje, para comunicarse con el resto de los miembros de su entorno.

La teoría que se aplica es la de Freinet ya que tanto en la educación primaria y secundaria se desea que los estudiantes e individuos sean libres. Freinet (2005). Desarrollando su imaginación y personalidad también puedan desarrollar su actividad creadora, humanizando el trabajo escolar para que sea atraído a maestros y alumnos; lo más importante en la técnica Freinet son las experiencias pues deben ser el material primordial de estudio en clases y no solo las lecturas, por que convierte a la escuela en parte de la vida.

Figura 5 Gráfico 44 - El Armagedón y la huida.

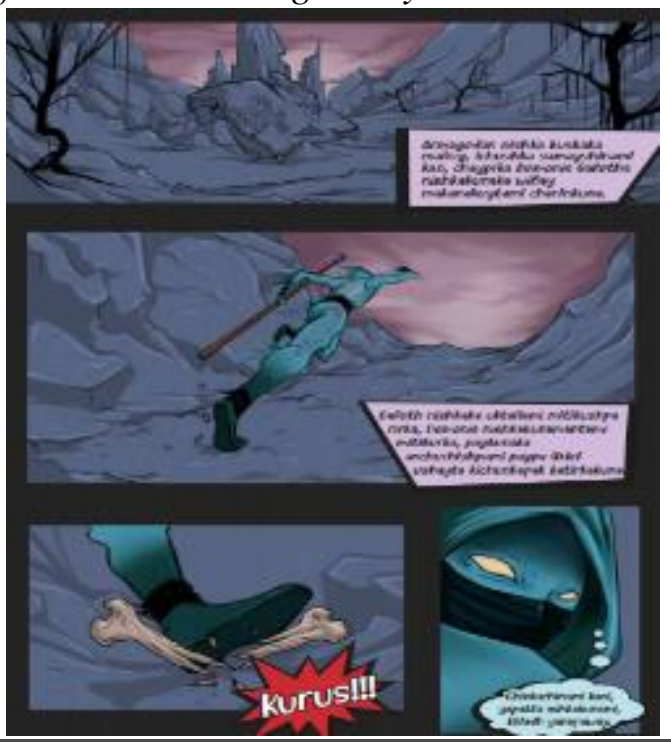

Elaborado por: Lara H., 2021. 
Figura 6 Gráfico 54- Un portal que une dos mundos.

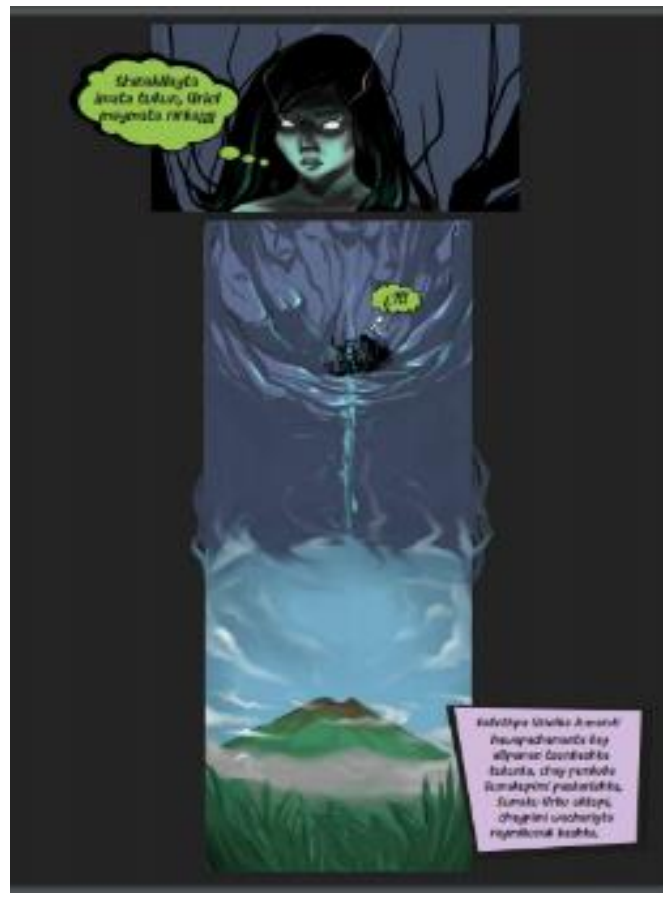

Elaborado por: Lara H., 2021.

Figura 7 Gráfico $N^{\circ} 58$ - El niño héroe Jumandi

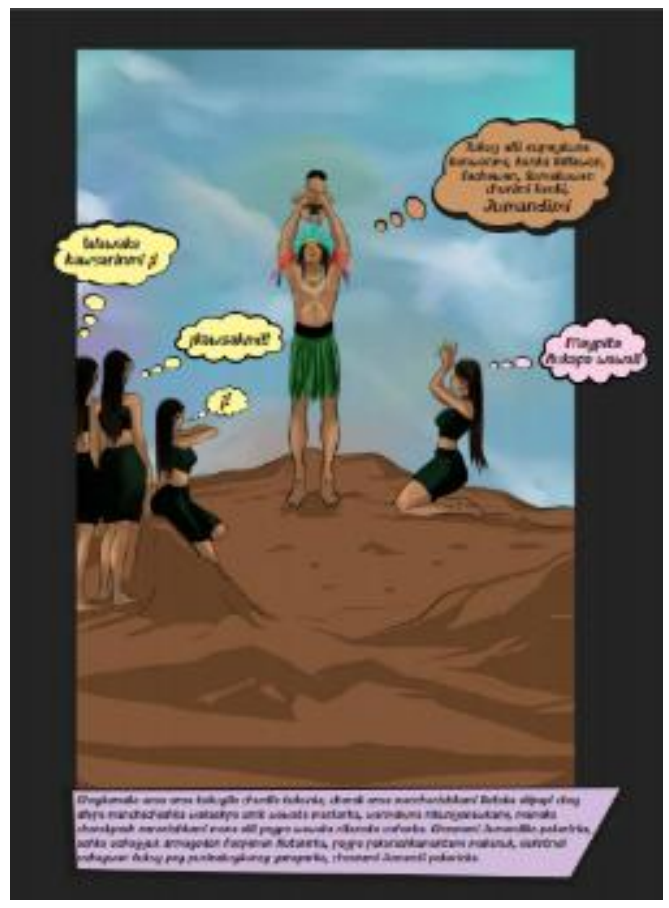

Autor: Lara H., 2021.

\section{Validación de la aplicación práctica de la propuesta}

El presente análisis se desarrolla a partir de entrevistas realizadas al grupo focal que corresponde a estudiantes y docente del séptimo año de educación básica de la 
unidad educativa intercultural bilingüe Intillacta, respecto a la aplicación del producto, cómic "Jumandi hijo del Sumaco (Sumakupak churi)", mediante plataforma zoom, las preguntas y los resultados fueron los siguientes:

\section{¿Cree que se recuperará los relatos de los abuelos si se transforman al kichwa?}

Los estudiantes responden que con relatos transformados a dibujos y en kichwa si se recupera la lengua, porque se motiva a leer más en el idioma redactado. En tanto los docentes manifiestan que los relatos de los abuelos, así relatados, son una manera más didáctica para fomentar el uso más frecuente del idioma en las aulas.

¿Cree que es importante identificar y rescatar los relatos de los abuelos y se traduzcan al kichwa para motivar su uso?

Los estudiantes mencionan que sí, es importante porque hay leyendas muy interesantes, los docentes manifiestan que a parte de la leyenda Jumandi, hay más relatos propios de los abuelos que sería bueno rescatar y contar en las aulas, para fomentar el uso del kichwa y no olvidar los relatos de los taitas.

\section{¿Es importante que los relatos se grafiquen a imágenes para que sean más motivadores al aprendizaje?}

Los estudiantes mencionan que observando las imágenes del cómic les gusta y les motiva a continuar con el relato y la historia, lo que les conlleva a continuar leyendo, aunque en este pilotaje su aplicación fue a través de plataformas virtuales, dado el proceso de confinamiento debido al Covid-19, los estudiantes manifestaron que les gustaría tener el cómic de manera física o en papel para revisarlo más a menudo, el cómic de Jumandi les motivado a releerlo nuevamente y observar las imágenes de la historia también. La concentración a la lectura durante la entrevista fue evidente; los docentes mencionan que los relatos iconográficos como el cómic en kichwa Jumandi motivan a los estudiantes a leer más, y que aplicará el examen de literatura en referencia a la lectura del cómic en mención.

\section{¿Les gusto el tema, les motivó a leer?}

A los estudiantes le llamó mucho la atención el cómic, solicitaron contar con un ejemplar en físico. Al docente le agradó la idea de contar con material didáctico para impartir sus clases de literatura en kichwa; además mencionó que era un instrumento para evaluar el nivel de kichwa en lectura y pronunciación de los estudiantes. 
Como hemos visto a través de las expresiones del grupo focal, los relatos iconográficos con imágenes manifestados a través de esta historia confirman la necesidad de promover la creación de material didáctico iconográfico que motive el aprendizaje y la lectura.

Puede encontrar el cómic en la versión kichwa digital en el siguiente link: https://drive.google.com/file/d/1hveRvQ4OxZI3f6DtjRLc836ygahcmK3_/view?usp =sharing

Puede encontrar el cómic en la versión español digital en el siguiente link: https://drive.google.com/file/d/1w8yztD97wSkzElx3qpuHQ3qoGwmS0JLf/view?us $\mathrm{p}=$ sharing

\section{CONCLUSIONES}

Con relación al objetivo general de: recuperar los relatos iconográficos propios; que revitalizan la lengua Kichwa, en la Unidad Educativa Intercultural Bilingüe "Intillacta", subnivel básico medio del séptimo año durante el tercer parcial del segundo quimestre del año lectivo 2020-2021 y la pregunta ¿Cómo los relatos iconográficos revitalizan la lengua Kichwa? Se concluye que los relatos iconográficos como "Jumandi", e "historias con la Guayusa" son los que más se les ha contado a las nuevas generaciones por parte de sus abuelos y padres, según la encuesta aplicada a estudiantes; de esta manera, recuperamos los relatos propios que existen en la actualidad. Estos relatos son grabados de forma oral, no existen escritos de relatos propiamente en el idioma kichwa; es por ello, que se proponen nuevos recursos pedagógicos de relatos iconográficos, para captar la atención de las nuevas generaciones y continuar con la práctica del idioma en la Educación Intercultural Bilingüe para revitalizar el uso de la lengua kichwa.

De acuerdo al primer objetivo específico: Identificar relatos propios para valorizar la cultura y la lengua Kichwa y la pregunta ¿Cuáles son los relatos propios que valorizan la cultura y la lengua Kichwa? Se concluye que si existen aún relatos propios identitarios de los ocho identificados el relato que más valoriza la cultura es el relato conocido de Jumandi, según las respuestas de la encuesta aplicada. Este relato valoriza la cultura porque hace referencia al guerrero indígena perteneciente a la cultura kichwa amazónico, que lideró la primera rebelión de Latinoamérica contra la invasión española a sus territorios. Lo identifican como un héroe, de apariencia 
física fuerte y sobre todo por ser líder, al identificar a los invasores como enemigo por el daño que causaban a las personas de la cultura en esa época y expulsarlos de su territorio.

Con relación al segundo objetivo específico: Describir la importancia de las narraciones escritas en su lengua propia para revitalizar la cultura kichwa y la pregunta ¿Qué importancia tiene las narraciones escritas en lengua kichwa para revitalizar la cultura? Se concluye que en la cultura kichwa de la amazonia la transmisión de las narraciones es mayormente oral; pero es importante iniciar la transmisión de relatos por medio de la escritura para dar un valor simbólico y abrir oportunidades para cambiar ideologías fuertemente enraizadas en las comunidades; al escribir su idioma se caracteriza una de las diferencias más significativas entre las sociedades occidentales y la cultura kichwa, y lo que es más importante, las nuevas generaciones pueden leer en su idioma materno, conservando el uso del kichwa y su cultura.

Con relación al tercer objetivo específico: Proponer un diseño de un relato iconográfico propio de la cultura Kichwa y a la pregunta ¿Qué tipo de relatos iconográficos propios podría revitalizar la cultura Kichwa? se concluye que el género a revitalizar es el de aventuras y el tipo de relatos es el de cantar de gesta y la leyenda; el relato propio a escribirse en idioma kichwa es sobre un héroe indígena de Jumandi, donde se relata aventuras y su trama es desarrollado según sus vivencias de victoria en guerra y sus hazañas.

En el grupo focal realizado con las autoridades, docente tutor y estudiantes del séptimo año de la Unidad Educativa Intercultural Bilingue Intillacta se concluye que: el cómic Jumandi (Hijo del Sumaco) llama la atención a los estudiantes, por cuanto motiva a leer en kichwa a los estudiantes con mayor entusiasmo y curiosidad. La mayoría de entrevistados menciona que es importante que los relatos se grafiquen y se transformen a imágenes, de esta forma es más motivador el aprendizaje. Los estudiantes creen que es importante rescatar los relatos de los abuelos y traducirlos al kichwa para motivar el uso del idioma. El docente tutor y autoridades creen que se puede recuperar los relatos de los abuelos sí se escriben en el idioma kichwa. 


\section{RECOMENDACIONES}

Según el trabajo de investigación desarrollado de acuerdo con los objetivos planteados se recomienda lo siguiente:

El Ministerio de Educación, para alcanzar una verdadera Educación Intercultural Bilingüe en el país, en las diferentes unidades educativas que pertenecen al SEIB; debe generar recursos didácticos escritos en el idioma materno de los estudiantes. Estos escritos deben ser innovadores que capten la atención de los educandos, que permitan el aprendizaje significativo de las asignaturas comunes y el fortalecimiento de su identidad cultural a través del idioma.

El Estado Ecuatoriano debe otorgar las facilidades para insertar proyectos innovadores escritos de revitalización de la lengua kichwa en las Unidades Educativas Interculturales donde tengan el currículo pertinente del idioma; cumpliendo así la constitución de un Estado Intercultural y plurinacional.

Los docentes deben procurar hablar más tiempo el idioma materno del kichwa dentro de la Unidad Educativa; así pues, debería hablarse en: las aulas, en los espacios de recreación, en los comedores, en los pasillos en minutos cívicos y en fiestas institucionales; con el fin de aportar a la preservación del idioma y ampliar espacios de uso emergentes por ser un idioma en peligro de extinción.

El relato iconográfico propio de la cultura kichwa es: el cómic "Jumandi" "Hijo del Sumaco"; un recurso pedagógico didáctico escrito y oral, desarrollado en idioma kichwa para fortalecer la identidad cultural y revitalizar el idioma en los niños, niñas, preadolescentes, y adolescentes que saben leer y escribir.

A la Universidad Tecnológica Indoamérica, sugerir la difusión y apoyo a esta investigación en opciones como: material educativo, folleto, revista, artículo científico o un libro.

Se devuelva los resultados de la presente investigación a la Unidad Educativa Intercultural Bilingüe Intillacta y a la nacionalidad indígena kichwa de la Amazonía por ser actores de la investigación.

\section{REFERENCIAS BIBLIOGRÁFICAS}

Alvarado, K. (2019. Análisis de la indumentaria de la Nacionalidad Kichwa Amazónico: Una aproximación a su significado (tesis de pregrado). Universidad Técnica de Ambato, Ambato, Ecuador. 
Alvarez Caicedo, T. A. (2012). Creación de un Comic de ciencia ficción basado en la caída del imperio romano tomando sus códigos históricos e iconográficos como referente conceptual (Bachelor's thesis, Universidad Autónoma de Occidente).

Arocutipa M. (2020). “Estrategias didácticas para la Revitalización de la oralidad del aimara en estudiantes de una educación inicial EIB Intercultural Bilingüe en la comunidad de Acora" (Tesis de pregrado). Universidad Peruana Cayetano Heredia, Lima, Perú.

Barragán Caro, A., Plazas Cepeda, N., \& Ramírez Vanegas, G. (2018). La lectura de imágenes: una herramienta para el pensamiento crítico. EDUCACIÓN Y CIENCIA, (19). https://doi.org/10.19053/01207105.7770

Bravo, E. (19 de mayo de 2017). La fiesta de la comunidad libre de extracción petrolera. El País. Recuperado de Bravo, E. (19 de mayo de 2017). La fiesta de la comunidad libre de extracción petrolera. El País. Recuperado de https://elpais.com/elpais/2017/05/16/planeta_futuro/1494940866_148482.htm 1

Brotons Capó, M. M., Murray-Mas, I., \& Blázquez-Salom, M. (1). Viaje de ida y vuelta, al mito. La contribución del cine a la formación de la iconografía turística de Mallorca. Anales De Geografía De La Universidad Complutense, 36(2), 203-236. https://doi.org/10.5209/AGUC.53583

Cerrato, B. (2015). La traducción feminista de la mitología cristiana: The Secret Gospel of Mary Magdalene, de Michèle Roberts (Tesis de maestría). Universidad de Salamanca, Salamanca.

Chalán Guincho, L. A. (2018). Implementación de materiales didácticos culturalmente sensibles para la revitalización del prestigio de la oralidad del idioma kichwa en educación inicial de la Unidad Educativa del Milenio Intercultural Bilingüe “Chibuleo” (Master's thesis, Pontificia Universidad Católica del Ecuador).

Chalán L. (2018). "Implementación de Materiales Didácticos Culturalmente Sensibles para la Revitalización del Prestigio de la Oralidad del Idioma Kichwa en Educación Inicial de la Unidad Educativa del Milenio 
Intercultural Bilingüe "Chibuleo" (Tesis de postgrado). Pontificia Universidad católica del Ecuador, Ambato, Ecuador.

Chávez A., Chenet M., \& Quispe W. (2019-09-30). Estrategias didácticas para revitalizar las lenguas originarias en estudiantes de la Universidad Nacional Intercultural de la Amazonía. San Gregorio. Recuperado de http://201.159.222.49/index.php/REVISTASANGREGORIO/article/view/10 $83 / 8-\mathrm{OCH}$

De Camilloni, A. (2007). Didáctica general y didácticas específicas. El saber didáctico, 23-39.

De Uriarte, C. G. (2018). DIBUJAR EL VIAJE: LA ICONOGRAFÍA RELATIVA A CANARIAS EN LOS RELATOS DE VIAJE FRANCESES DEL SIGLO XIX. Studii şi cercetari filologice. Seria limbi romanice, (24), 7-18.

Decolonial una década después. Calle 14: revista de investigación en el campo del arte 14(25). pp. 14-32. DOI: https://doi.org/10.14483/21450706.14132

EFE. (17 de diciembre de 2019). ONU Clausura año Internacional de las Lenguas Indígenas. PRIMICIAS. Recuperado de https://www.primicias.ec/noticias/sociedad/onu-clausura-internacionallenguas-indigenas/

Eilers, V. (2020). Aspectos del desarrollo de la lingüística española a través de los siglos. Germany, Germany: Buske. Recuperado de https://books.google.com.ec/books?id=gF8LEAAAQBAJ\&pg=PA58\&dq=tra nsmision+del+idioma+concepto\&hl=es\&sa=X\&ved=2ahUKEwi2qYWrwpD uAhUHVN8KHRKPBxQQuwUwAXoECAIQBg\#v=onepage $\& q=$ transmisio n\%20del\%20idioma\%20concepto\&f=false

Flacso Ecuador. (2016). Etnohistoria de los pueblos y nacionalidades del Ecuador (2). Recuperado de https://www.care.org.ec/wpcontent/uploads/2016/02/Modulo-2.pdf

Flores y Córdova (2012). Guía de revitalización lingüística: para una gestión formada informada. Recuperado de https://www.academia.edu/14274658/Gu\%C3\%ADa_para_la_Revitalizaci\% C3\%B3n_Ling\%C3\%BC\%C3\%ADstica_Para_una_Gesti\%C3\%B3n_Formad a_e_Informada 
Freinet, C. (2005). Técnicas Freinet de la escuela moderna. Buenos Aires: Siglo XXI Editores. Latorre, A. 2003. La investigación-acción. Conocer y cambiar la práctica educativa. Graó: Barcelona.

Garcés, F. (2020). La revitalización de las lenguas Indígenas del Ecuador: una tarea de todos.

García-Azkoaga, I.M (2019-01-01). Didáctica de las lenguas y educación bi/plurilingüe: algunos retos para la EIB. Enunciación, 24(1), 45-60. doi: http://doi.org/10.14483/22486798.13263

González Rial, Ramiro y Haye, Andrés. (2015). Alteración del concepto de etnicidad desde la experiencia de las tejedoras mapuche del sur de Chile. Psicologia USP, 26 (3), 441-452.

Grefa, J. (24 de enero de 2019). Unidad Educativa Intillacta. Tena, Napo, Ecuador. Recuperado el 07 de junio de 2021, de https://educativeinti.wordpress.com/blog/

Hernández, Magaña \& Melendez, J. (2017). Análisis semiótico del cartelismo sociopolítico realizado para el período de la guerra civil de El Salvador (1980-1992) expuesto en el Museo de la Palabra y la Imagen (tesis de pregrado). Universidad Dr. José Matías Delgado, Antiguo Cuscatlán.

Hungrìa I. (5 de marzo del 2021). ¿Sabías que en el Ecuador se hablan 14 lenguas ancestrales?. EL TELÉGRAFO. Recuperado de https://www.eltelegrafo.com.ec/noticias/buen/1/sabias-que-en-ecuador-sehablan-14-lenguas-ancestrales

Isabel., M. y López, R. (2005). INTRODUCCIÓN GENERAL A LOS ESTUDIOS ICONOGRÁFICOS Y A SU METODOLOGÍA.

Lopez V. \& Koshinen A. (2009, diciembre). La revitalización de la Lengua y Cultura Garífuna a través de la Educación. Revitalización Lingüística y cultural. Recuperado de https://www.researchgate.net/publication/277824314_LA_REVITALIZACIo N_DE_LA_LENGUA_Y_CULTURA_GARIFUNA_A_TRAVES_DE_LA_ EDUCACION

Maqueo, A. M. (2005). El enfoque comunicativo: de la teoría a la práctica Recuperado de https://books.google.com.ec/books?id=gYndQID- 
E9YC\&pg=PA41\&dq=aprendizaje+social+de+las+lenguas \&hl=es419\&sa=X\&ved=2ahUKEwiGnYmu2dHuAhVwGFkFHd82BqkQ6AEwAHo ECAAQAg\#v=onepage $\& \mathrm{q}=$ aprendizaje $\% 20$ social $\% 20 \mathrm{de} \% 201$ as $\% 20$ lenguas $\& \mathrm{f}=$ false

Mignolo, Walter D. (2019). Reconstitución epistémica/estética: la aesthesis

Ministerio de educación. (2017). ISHKAY SHIMI KAWSAYPURA MAMALLAKTAYUKKUNAPA YACHAYÑAN - La vida entre dos idiomas hacia el sendero de los conocimientos de los países (s/n). Recuperado de https://educacion.gob.ec/wpcontent/uploads/downloads/2017/03/KICHWA_CNIB_2017.

Ministerio de Educación. (2021). Educación Intercultural Bilingüe (s/n). Recuperado de https://educacion.gob.ec/educacion-intercultural-bilingue-princ/

Misinche, F. (26 de noviembre de 2018). Nacionalidad Kichwa celebrará al Niño Jista en Unión Base. El comercio. Recuperado de https://www.elcomercio.com/tendencias/nacionalidad-kichwa-celebracionnino-jista.html

Mora, V. (jueves, 11 de abril de 2013). Nacionalidad Kichwas del Oriente [Mensaje en un blog]. Recuperado de https://vicentemorapablomontalvo.blogspot.com/2013/04/nacionalidadkichwa-de-laamazonia.html?showComment=1610910653015\#c5056457056897597678

Pool, B. A. (2015, 09 de julio). El aporte del estudio numismático de la moneda romana imperial a la comprensión de la Mitología Clásica. OMNI Revista Numismática. Recuperado de http://www.wikimoneda.com/ojs/index.php/omni/article/view/68/64

Puebla, M. M. (2019, July). El poder del relato, a la luz de un análisis iconográfico medieval. In [GKA ARTS 2019] Congreso Internacional de Artes y Culturas.

Rivas, A. (2018). "Los jóvenes indígenas en Ecuador": El reto de la lectura y la escritura en la Pontificia Universidad Javeriana de Cali. En H. Mondragón (Ed.), Leer, comprender, debatir, escribir. Escritura de artículos científicos por profesores universitarios (pp. 53-62). Cali, Valle del Cauca: Sello Editorial Javeriano. 
Rodríguez, M. I. (2006). Introducción general a los estudios iconográficos y a au metodología. Ciudad, País: Instituto Municipal de Estudios Iconográfico.

Rojas Ortiz, L. M. ., \& Angel Méric, O. G. . (2020). Anomia y esquizofrenia cultural, las máscaras Kichwas y Shuar en Puyo, Ecuador. REVISTA CIENTÍFICA ECOCIENCIA, 7(6), 83-105. https://doi.org/10.21855/ecociencia.76.392

Rojas Torres, K. E. (2017). Desarrollo de una plataforma virtual para la revitalización de la lengua kukama kukamiria de Perú.

San Martín, J. (2015). Antropología Filosófica II. Vida humana, persona y cultura Recuperado de https://books.google.com.ec/books?id=A5ZBgAAQBAJ\&pg=PT363\&dq=Valor+cultural\&hl=es\&sa=X\&ved=2ahUKE wjoq9mDsZDuAhVCmAKHdIgC0sQ6AEwBXoECAMQAg\#v=onepage\&q $=$ Valor $\% 20$ cultural $\& \mathrm{f}=$ false

Taylor, Ch. (2015). La era secular: Tomo II, Volumen 2. Barcelona, España: Gedisa, S.A.

Torres, V., Diaz, D., Lema, D., Ibadango, M. F., \& Manosalvas, K. (2020). Focus group y grupos de discusión como técnicas cualitativas para la creación de espacios de diálogo y debate en la revitalización de lenguas ancestrales. REVISTA CIENTÍFICA AXIOMA, (22), 62-68.

TorresV., DiazD., LemaD., IbadangoM. F., \& ManosalvasK. (2020). Focus group y grupos de discusión como técnicas cualitativas para la creación de espacios de diálogo y debate en la revitalización de lenguas ancestrales. REVISTA CIENTÍFICA AXIOMA, (22), 62-68. Recuperado a partir de http://pucesinews.pucesi.edu.ec/index.php/axioma/article/view/601

Unidad Educativa Intercultural Bilingue Intillacta. (2019). Propuesta Currícular Innovadora. Tena: Unidad Educativa Intillacta.

Valdivieso Kastner, Natalia Catalina. (2015, Febrero). Identidad, territorio y petróleo: la comuna Kichwa Limoncocha y la extracción de crudo. Tesis de maestría, FLACSO, Ecuador.

Verdugo, A. C., \& Escobar, M. E. R. (2018). Análisis de idoneidad didáctica sobre la geometría espacial en el currículo nacional intercultural bilingüe de Ecuador. In Revista Anales (Vol. 1, No. 376, pp. 67-80). 
Villaseñor F. S. (2009). Iconografía marginal en Castilla 1454-1492. Madrid, España: Centro superior de investigaciones científicas.

Zapata Cárdenas, María Isabel (2019). Camiones de Escalera: iconografía visual campesina rodante como expresión viva de la cultura y gráfica popular colombiana. adComunica. Revista Científica de Estrategias, Tendencias e Innovación en Comunicación, (17), 187-207. DOI: http://dx.doi.org/10.6035/2174-0992.2019.17.1

Zurita M., Ponce J. y Guachamin M. (2018). Alimentos ricos y nutritivos de la chagra kichwa. Tena, Ecuador: Universidad Regional Amazónica Ikiam.

Zymla, H. G. (2017). Aristóteles y la Cortesana: iconografía del filósofo metafísico dominado por el deseo entre los siglos XIII Y XVI. Revista digital de iconografía medieval, 9(17), 7-44. 